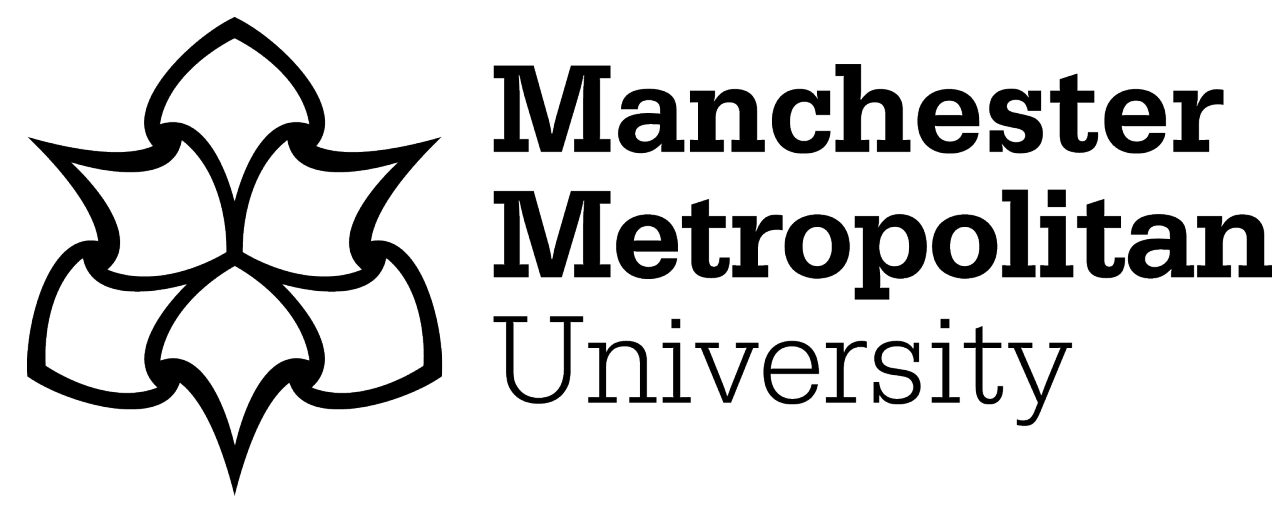

Dobbin, Nick, Hunwicks, Richard, Highton, Jamie and Twist, Craig (2017) Validity of a Jump Mat for assessing Countermovement Jump Performance in Elite Rugby Players. International Journal of Sports Medicine, 38 (02). pp. 99-104. ISSN 0172-4622

Downloaded from: https://e-space.mmu.ac.uk/621565/

Version: Accepted Version

Publisher: Georg Thieme

DOI: https://doi.org/10.1055/s-0042-118313

Please cite the published version 


\title{
Validity of a Jump Mat for assessing Countermovement Jump Performance in Elite Rugby Players
}

\author{
N. Dobbin ${ }^{1,2}$, R. Hunwicks², J. Highton ${ }^{1}$, C. Twist ${ }^{1}$ \\ ${ }^{1}$ Sport and Exercise Science, University of Chester, Chester, United Kingdom of Great Britain and Northern Ireland \\ ${ }^{2}$ Rugby Football League, Human Performance, Leeds, United Kingdom of Great Britain and Northern Ireland
}

\begin{abstract}
$\nabla$

This study determined the validity of the Just Jump System ${ }^{\circledR}(\mathrm{JJS})$ for measuring flight time, jump height and peak power output (PPO) in elite rugby league players. 37 elite rugby league players performed 6 countermovement jumps (CMJ; 3 with and 3 without arms) on a jump mat and force platform. A sub-sample $(\mathrm{n}=28)$ was used to cross-validate the equations for flight time, jump height and PPO. The JJS systematically overestimated flight time and jump height compared to the force platform $(\mathrm{P}<0.05)$, but demonstrated strong associations for flight time (with
\end{abstract}

\section{Introduction}

$\nabla$

Rugby league is a multiple sprint collision sport that requires highly developed physical qualities $[5,15,23,33]$. Of these, lower-body power has been identified as an essential quality for rugby league players [5,10-14], showing strong associations with successful skill execution (i.e., tackling proficiency) $[11,12,33,38]$ and reducing post-match fatigue $[20,21]$. Countermovement jump (CMJ) performance differentiates between starters and non-starters [12], playing standard (club cf. international) [35] and playing position $[13,22]$. Therefore, $C M J$ is regularly employed by practitioners to assess the effectiveness of a conditioning programme $[29,34,26,39]$, to profile players and identify talent [35] and to monitor recovery status $[21,27,36,37]$.

Whereas video analysis and force platforms are recognised as criterion methods for measuring jump height, flight time and muscle power, these are expensive and not easily accessible for most rugby league clubs $[18,25,31]$. Flight time and jump height during the $\mathrm{CMJ}$ are routinely measured by rugby league practitioners using commercially available equipment such as the Just
$\mathrm{R}^{2}=0.938$; without $\mathrm{R}^{2}=0.972$ ) and jump height (with $\mathrm{R}^{2}=0.945$; without $\mathrm{R}^{2}=0.987$ ). Our equations revealed no systematic difference between corrected and force platform scores and an improved the agreement for flight time (Ratio limits of agreement: with 1.00 vs. 1.36; without 1.00 vs. 1.16) and jump height (with 1.01 vs. 1.34 ; without 1.01 vs. 1.15), meaning that our equations can be used to correct JJS scores for elite rugby players. While our equation improved the estimation of PPO (with 1.02; without 1.01) compared to existing equations (Harman: 1.20; Sayers: 1.04 ), this only accounted for 64 and $69 \%$ of PPO.

Jump System ${ }^{\circledR}$ (JJS), to provide estimates of jump performance $[28,30,39]$. However, the ability of the JJS to accurately measure flight time and jump height has recently been questioned $[28,39]$. The authors reported that flight time and jump height measured on the JJS and force platform are highly related but that flight time is on average $105 \mathrm{~ms}$ longer on the JJS resulting in an overestimation of jump height $[28,39]$. Whilst both studies provided a correction equation for the measurement of jump height, neither provided a correction equation for the measurement of flight time, which has been reported to be a more reliable determinant of jump performance [6]. Also, the equations provided were not crossvalidated using a sub-sample and therefore their agreement with the criterion method is unknown. Although the authors $[28,39]$ reported a strong correlation between methods, the random error associated with these measurements was not assessed and therefore the application of these corrected equations in the applied environment also remains unknown.

As jump mats are unable to measure muscle power, several prediction equations have been developed that allow practitioners to calculate 
muscle power using jump height and body mass $[4,7,16,32]$. Whilst some prediction equations demonstrate no systematic difference to power recorded on a force platform [16], the accuracy of the equation is highly dependent upon the population it is derived from [25]. For example, the use of previously established prediction equations $[16,32]$ for estimating muscle power in specifically trained team sport athletes are known to underestimate true PPO by $3.3-19.4 \%[8,18]$.

In professional rugby league, where the accurate assessment of CMJ performance using a jump mat seems important, recently developed prediction equations $[28,39]$ are not suitable given that they were developed using non-elite populations. Moreover, where the assessment of muscle power is of interest [38] the application of established prediction equations might result in an underestimation of the player's actual PPO. Therefore, the aims of this study were to: a) quantify the difference in jump height and flight time between the JJS and force platform and, if required, develop and cross-validate a correction equation for elite rugby league players; and b) develop and cross-validate a prediction equation for PPO in elite rugby league players.

\section{Material \& Methods}

Participants and design

With institutional ethics approval and informed consent, 37 elite senior rugby league players from 2 professional Super League teams (age $=23.3 \pm 4.0 \mathrm{y}$, stature $=182.0 \pm 5.5 \mathrm{~cm}$, body mass $=96.8 \pm 9.0 \mathrm{~kg}$ ) participated in this study. A sub-sample of 28 elite senior players from one professional Super League club (age $=23.4 \pm 4.3 \mathrm{y}$, stature $=181.9 \pm 5.5 \mathrm{~cm}$, body mass $=96.1 \pm$ $9.0 \mathrm{~kg}$ ) was later recruited to cross-validate the equations for jump height, flight time and PPO. All testing procedures were conducted in accordance with the ethical standards of the International Journal of Sports Medicine [17].

In one visit, participants completed one practice jump followed by 6 CMJs, 3 using their arms (with arms; $n=111$ ) and 3 with their hands on their hips (without arms; $n=108$ ), interspersed by $60 \mathrm{~s}$ recovery between jumps. All participants were familiar with the procedures as this was part of their weekly monitoring processes. To cross-validate the data, the sub-sample of participants attended a second session 5 days after the first at a similar time of day $( \pm 2 \mathrm{~h})$ and completed $2 \mathrm{CMJs}$, one with $(n=28)$ and one without arms $(n=28)$, interspersed by 60 s recovery.

\section{Procedures}

For the CMJ, participants maintained a stance with feet positioned shoulder width apart before flexing their knees in a rapid downward motion and extending into the jump. To standardise the jumps participants had to have been judged to reach approximately $90^{\circ}$ knee flexion [ 37] a nd keep their legs straight throughout the jump (i.e., not lifting knees or bringing their heels towards their buttocks). Those jumps ( $n=3$ without arms) that did not meet these criteria were excluded from the analysis. Each jump was performed on a timing mat (Just Jump System, Probotics, Huntsville, Alabama, USA) that was positioned on top of a $600 \times 600 \mathrm{~mm}$ uni-axial calibrated force platform (HUR Labs, FP4, Tampere, Finland) sampling at $1200 \mathrm{~Hz}$. The jump mat was positioned on the force platform before calibration and allowed both apparatus to record measurements simultaneously [25] Both flight time and jump height derived from the JJS and force platform were displayed on a hand held computer and on cus- tom software (HUR Labs Force Platform Software Suite), with jump height calculated using the following equation [24]:

Jump height $=\left(\right.$ flight time $\left.{ }^{2} \times g\right) 8^{-1}$

In this equation, $g$ denotes the acceleration of gravity $\left(9.81 \mathrm{~m} \times \mathrm{s}^{-2}\right)$. For the JJS, flight time was measured as the time the participant was in the air and was detected by the micro switches embedded within the mat sampling at $100 \mathrm{~Hz}$ [39]. For the force platform, flight time was also determined as the time the participant was in the air with $<5 \mathrm{~N}$ being used to detect take-off and $>50 \mathrm{~N}$ for landing. To ascertain PPO the force platform used the following in-built equations:

Force $=$ average force at point of take - off and landing

Momentum $=($ momentum + average force $) \times(1 / 1200)$

Impulse $=($ momentum $\times$ impulse $/$ weight $\times 1) \times(1 / 1200)$

$\mathrm{PPO}=($ force $\times$ impulse $/$ mass $)$

The within-session coefficient of variation for flight time during the first session was 4.8 and $5.0 \%$ for with and without arms, respectively.

\section{Statistical analyses}

Data were initially checked for normality via the KolmogorovSmirnov statistic before using Pearson product-moment correlation ( $r$-value) to check for heteroscedastic errors. Data that demonstrated heteroscadascity was log-transformed to reduce the error [2]. Paired sample $t$-tests were used to calculate differences (biases) between means of measurement methods. In order to make comparisons, the coefficient of variation (CV: SD/ Mean $\times 100$ ) was also used to assess validity and was quantified in accordance with previous research [2]. Linear and multiple regression analysis was used to determine a correction equation for flight time and jump height and to develop a new prediction equation for PPO. Collinearity was assessed before the multiple regression and indicated that there was a high collinearity between jump height and flight time (with $r=0.992$; without $r=0.996$ ), hence jump height was excluded. Weak collinearity (with $r=-0.366$; without $r=-0.292$ ) existed between flight time and body mass, with both variables contributing significantly to predictive model. Data are reported as mean and standard deviation(s) throughout and analysed using SPSS for Windows (Version 22.0, 2013).

\section{Results}

There was a positive relationship between CMJ flight time derived from the JJS and force platform with $(r=0.969, P<0.001)$ and without $(r=0.986, P<0.001)$ arms, which resulted in adjusted coefficient of determinations $\left(\mathrm{R}^{2}\right)$ of 0.938 and 0.972 , respectively ( $\bullet$ Fig. 1). A positive relationship was also present between jump height derived from the JJS and force platform with $(r=0.972, P<0.001)$ and without arms $(r=0.994, P<0.001)$, resulting in adjusted $R^{2}$ values of 0.945 and 0.988 , respectively. Despite the strong relationship between methods, ratio LoA indicated that there was a systematic $(P<0.05)$ overestimation of 
flight time and jump height, with and without arms using the JJS compared to the force platform ( $\bullet$ Table 1 ). Given the near perfect $R^{2}$ between the 2 systems, linear regression analysis was used to establish 4 correction equations, allowing practitioners within the field of rugby league to accurately measure jump height and/or flight time with and without arms from the JJS (० Fig. 1).

The adjusted $\mathrm{R}^{2}$ between criterion and corrected flight time and jump height with and without arms were strong ( $\bullet$ Fig. 1) and demonstrated a reduced systematic bias $(P>0.05)$ compared to the uncorrected scores ( $\bullet$ Table 2 ). Cross-validation analyses for flight time and jump height revealed an adjusted $\mathrm{R}^{2}$ (flight time: with 0.924; without 0.966; jump height: with 0.914; without 0.937 ) that represented a shrinkage of $2.22,2.23,2.56$ and $3.60 \%$, respectively.

Stepwise regression analysis was used to predict PPO (W) from flight time (s) and body mass $(\mathrm{kg})$. The 2 predictor variables accounted for a significant proportion of variability in PPO, with (adjusted $\mathrm{R}^{2}=0.642, \quad F=96.52, \quad P<0.001$ ) and without arms (adjusted $\left.R^{2}=0.691, F=111.34, P<0.001\right)$. However, the regression model for $\mathrm{PPO}$ with $\left(\mathrm{PP}_{\text {est }}=12413.90 \times(\right.$ flight time $)+58.77 \times$ (body mass) -7383.05$)$ and without arms $\left(\mathrm{PP}_{\mathrm{est}}=8167.97 \times\right.$ (flight time) $+49.13 \times$ (body mass) -4390.76 ) showed a large degree of random error ( $\bullet$ Table 3 ). Cross-validation analysis revealed an adjusted $\mathrm{R}^{2}$ (with 0.613 ; without 0.654 ) that represented shrinkage of 4.52 and $5.36 \%$ relative to the cross-validation model (with $64.2 \%$; without $69.1 \%$ ).

\section{Discussion}

$\nabla$

The primary aim of this study was to establish the criterion validity of the JJS against a force platform for measuring flight time and jump height during a $\mathrm{CMJ}$ in elite rugby league players. In accordance with previous studies $[28,39]$, we report a systematic overestimation of flight time and jump height derived from the JJS. On average, flight time was $85 \mathrm{~ms}$ longer using the $\mathrm{JJS}$ compared to the force platform, which resulted in an overestimated jump height of $\sim 13 \mathrm{~cm}$. The ratio LoA indicated that for a player with a flight time of $0.50 \mathrm{~s}$ using the force platform, they could, in the worst case scenario, achieve a value between 0.56 and $0.59 \mathrm{~s}$ with and 0.56 and $0.60 \mathrm{~s}$ without arms when using the JJS. Furthermore, the ratio LoA for jump height indicated that a player who jumped $30 \mathrm{~cm}$ using the force platform, could jump between 37.9 and $42.6 \mathrm{~cm}$ and 38.9 and $42.8 \mathrm{~cm}$ with and without arms, respectively, when measured using the JJS. Our findings reaffirm previous work $[28,39]$ that the JJS does not provide a valid measure of flight time or jump height during a CMJ.

Several reasons might explain the observed differences between measurement systems. McMahon et al. [28] suggested that jump height might have been overestimated due to the JJS requiring a large minimal force for the microswitches within the mat to detect the take-off and landing during the CMJ. Whilst this might explain some of the difference, it is important to note that the JJS does not directly measure jump height but calculates this from fight time. Therefore, any delay in the microswitches to detect the landing is likely to results in a large overestimation in flight time. Whitmere et al. [39] proposed that due to the consistent differences between methods, approximately $100 \mathrm{~ms}$ have been added

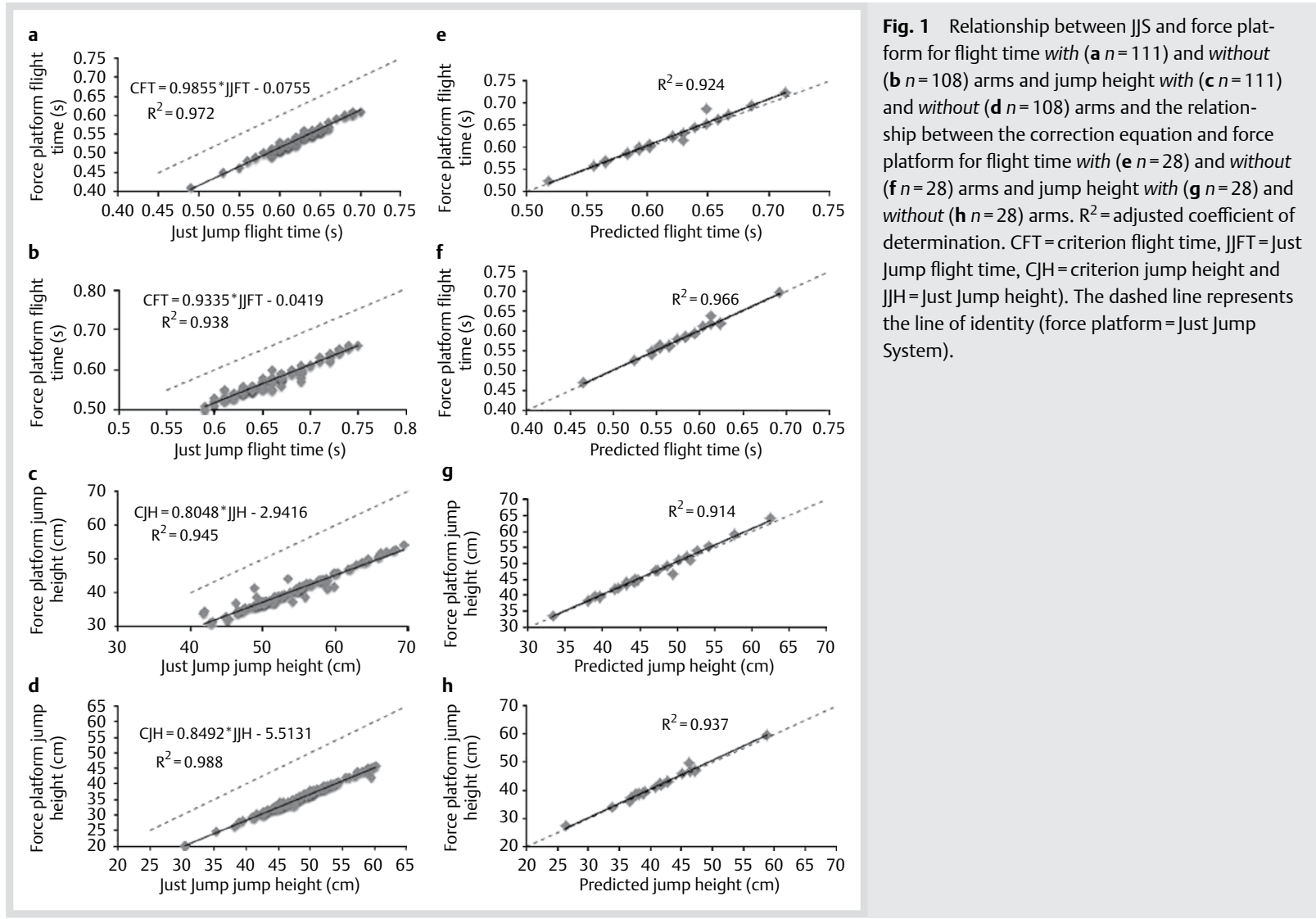




\begin{tabular}{|c|c|c|c|c|c|}
\hline & Just Jump ${ }^{\circledR}$ & Force platform & Ratio $95 \%$ LoA & CV\% & Adjusted $\mathbf{R}^{2}$ \\
\hline \multicolumn{6}{|l|}{ Jump height $(\mathrm{cm})$} \\
\hline With arms & $53.69 \pm 6.14 *$ & $40.28 \pm 5.10$ & $1.34 \times 1 \div 1.06$ & 18.68 & 0.938 \\
\hline Without arms & $48.62 \pm 5.51^{*}$ & $35.81 \pm 4.72$ & $1.15 \times \mid \div 1.03$ & 19.48 & 0.972 \\
\hline \multicolumn{6}{|l|}{ Flight time (s) } \\
\hline With arms & $0.66 \pm 0.04 *$ & $0.57 \pm 0.04$ & $1.36 \times 1 \div 1.05$ & 9.15 & 0.945 \\
\hline Without arms & $0.62 \pm 0.03^{*}$ & $0.54 \pm 0.03$ & $1.16 \times \mid \div 1.03$ & 9.40 & 0.988 \\
\hline
\end{tabular}

Table 1 Validity of Just Jump ${ }^{\circledR}$ against force platform to measure jump height and flight time.

LoA $=$ limits of agreement. CV\% $=$ coefficient of variation. * Significantly higher than criterion $(P<0.05)$

\begin{tabular}{|llllll|} 
& Corrected & Force platform & $\mathbf{9 5 \% \text { Ratio LoA }}$ & CV\% & Adjusted R $^{2}$ \\
\hline $\begin{array}{l}\text { Jump height }(\mathrm{cm}) \\
\text { With arms }\end{array}$ & $45.99 \pm 5.69$ & $46.36 \pm 6.06$ & $1.01 \times / \div 1.17$ & 14.35 & 0.924 \\
$\quad \begin{array}{l}\text { Without arms } \\
\text { Flight time (s) }\end{array}$ & $41.00 \pm 4.87$ & $41.36 \pm 5.70$ & $1.01 \times / \div 1.19$ & 14.43 & 0.966 \\
$\quad$ With Arms & $0.61 \pm 0.04$ & $0.62 \pm 0.05$ & $1.00 \times / \div 1.13$ & 7.34 & 0.914 \\
\hline Without arms & $0.58 \pm 0.03$ & $0.58 \pm 0.41$ & $1.00 \times / \div 1.11$ & 7.20 & 0.937 \\
\hline
\end{tabular}

Table 2 Validity of correction equations against measured jump height and flight time using crossvalidation sample.

LoA $=$ limits of agreement. CV\% = coefficient of variation. ${ }^{*}$ Significantly higher than criterion $(P<0.05)$. Shrinkage $=2.22$ and $2.23 \%$ for jump height and 2.56 and 3.60 for flight time with and without arms, respectively

\begin{tabular}{|c|c|c|c|c|c|}
\hline & Peak power output (W) & SEE & Ratio $95 \%$ LoA & CV\% & Adjusted $\mathrm{R}^{2}$ \\
\hline \multicolumn{6}{|l|}{ Measured } \\
\hline With arms & $5846.9 \pm 651.6$ & - & - & & - \\
\hline Without arms & $5048.2 \pm 589.0$ & - & - & & - \\
\hline \multicolumn{6}{|l|}{ Predicted } \\
\hline With arms & $5930.0 \pm 603.2$ & 410.6 & $1.02 \times / \div 1.17$ & 10.69 & 0.613 \\
\hline Without arms & $5060.4 \pm 479.0$ & 310.0 & $1.01 \times / \div 1.15$ & 10.91 & 0.654 \\
\hline \multicolumn{6}{|c|}{ Harman et al. (1991) } \\
\hline Without arms & $4205.6 \pm 417.3^{*}$ & - & $1.20 \times 1 \div 1.16$ & 14.55 & 0.77 \\
\hline \multicolumn{6}{|c|}{ Sayers et al. (1999) } \\
\hline Without arms & $4837.7 \pm 458.3^{*}$ & - & $1.04 \times / \div 1.16$ & 11.18 & 0.78 \\
\hline
\end{tabular}

$\mathrm{SEE}=$ standard error of estimate. $\mathrm{LOA}=$ limits of agreement. $\mathrm{CV} \%=$ coefficient of variation. ${ }^{*}$ Significantly different to actual peak power $(P<0.05)$. Shrinkage $=4.52$ and $5.36 \%$ for with and without arms, respectively

to the algorithm used to calculate flight time. However, as the algorithms used are unknown, it is difficult to conclude that this is the case, despite our results showing a similar trend. The observed difference might a lso be explained by the higher sampling frequency of the force platform $(1200 \mathrm{~Hz})$ compared to the JJS $(100 \mathrm{~Hz})$. Such large differences are likely to result in different detection rates during the take-off and landing, influencing the accuracy of flight time and subsequently jump height.

Using the correction equations, results revealed that the accuracy of flight time and jump height were improved ( $\bullet$ Table 2 ) and could, therefore, be used by practitioners to accurately measure jump performance. The results indicate that the correction equations removed the over-estimation created by the JJS and reduced the mean bias. As a result, the potential range of scores achieved now encompasses the measured score and therefore, one can be $95 \%$ confident that the same participant who scored $30 \mathrm{~cm}$ on their first trial (with arms), could score between 25.8 and $35.4 \mathrm{~cm}$ during their second trial. Based on these calculations, it appears that the JJS and the correction equation are, in some cases, not sensitive enough to detect small, but potentially meaningful changes in jump performance. For example, Gabbett [14] reported a $4.2 \mathrm{~cm}$ increase in CMJ performance in junior rugby league players after a 14-week training intervention. Based on our analysis, it is possible, in some cases, this improvement would not be detected using the JJS or the correction equation due to the large random error associated with this method.
The second aim of this study was to develop an equation for predicting PPO in elite rugby league players. Whereas previous work has used jump height $[28,39]$, our analysis indicated that flight time was a better predictor of PPO. The use of flight time is somewhat understandable since it is measured directly by the $\mathrm{JJS}$ and is a more reliable performance indicator of jump performance [6]. The results support previous observations $[8,18]$ that PPO estimated using equations derived from non-elite populations underestimates true PPO in well-trained athletes [16,32]. The ratio LoA indicated that there was a systematic under-estimation of PPO when using the Harman et al. [16] and Sayers et al. [32] equations, but not systematically different when using our equations. This finding suggests that when applied to elite rugby league players, these equations are an improvement on those of Harman et al. [16] and Sayers et al. [32]. However, the results indicate that a player who achieved a PPO of $5000 \mathrm{~W}$ on their first visit (with arms), could, in the worst case scenario, score as low as $4359 \mathrm{~W}$ or as a high as $5967 \mathrm{~W}$ during a second visit. It is likely this degree of random error is too large to detect small but meaningful changes in lower-body power [1]. For example, Speranza et al. [33] reported an improvement in CMJ PPO of $\sim 205 \mathrm{~W}$ in senior rugby league players after a 15 -week preseason training period. Based on our analysis, it is possible, in some cases, that this improvement in PPO would not be detected using our prediction equation due to the large random error associated with this measure. 
Our results support the notion that generalised equations to estimate PPO developed using non-elite populations are unsuitable for elite rugby league players. This might, in part, be explained by the strong emphasis placed on strength and power development in rugby league players [3] that leads to improved neuromuscular characteristics when compared to non-elite populations. Indeed, those athletes requiring highly developed speed, strength and power, have a higher proportion of fast twitch muscle fibres [19] and are capable of producing large ground reaction forces through increased muscle mass, muscle fibre recruitment, co-ordination and firing frequency [9] compared to non-elite populations. These enhanced neuromuscular characteristics mean that elite rugby league players are likely to have an enhanced ability to produce greater force and power during explosive movements such as the CMJ compared to nonelite athletes. This might explain the systematic underestimation of PPO when using equations based on non-elite athletes, suggesting that a more homogenous equation is required. As flight time and body mass only accounted for 64 and $69 \%$ of PPO, it is possible that differences in neuromuscular characteristics between players, due different training experiences and genetic differences, could have contributed to the variation in PPO.

\section{Limitations}

Whilst our equations for correcting flight time and jump height removed the systematic over-estimation, the large random error associated with these equations could limit their usefulness for detecting small, but potentially meaningful changes in CMJ performance. The PPO prediction equation was an improvement on those previously reported when working with elite rugby league players, but also demonstrated a large random error, which too could limit its application in the applied environment. It is important to note that the correction equations for flight time and jump height, as well as the prediction equation for PPO are specific to the JJS and caution should be taken when applying these equations to other jump mats.

\section{Conclusion}

\section{$\nabla$}

Although attempts have been made to create correction equations for the JJS $[28,39]$, these authors did not cross-validate their equations or assess the agreement between the equations and force platform. In contrast, the present study established and cross-validated 4 equations that can be used by applied practitioners to accurately measure jump height and/or flight time when using the JJS. Furthermore, this is the first study to use flight time within the PPO equation. As flight time is measured rather than predicted, this is likely to provide a more accurate and reliable measure of jump performance and therefore should be used for predicting PPO. The results indicate that the prediction equations to estimate PPO of elite rugby league players are an improvement on those reported previously using nonelite participants. However, as the $\mathrm{R}^{2}$ between the force platform and prediction equations with and without arms only accounted for 64 and $69 \%$ of PPO, it is reasonable to suggest that PPO cannot be estimated accurately using a JJS and that practitioners requiring measures of PPO should use a force platform.
Conflict of interest: The author have no conflict of interrest to declare.

\section{References}

1 Ache-Dias J, Pupo JD, Ghelle RG, Külkamp W, Moro ARP. Power output prediction from jump height and body mass does not appropriately categorize or rank athletes. J Strength Cond Res 2015; 30: 818-824

2 Atkinson G, Nevill AM. Statistical methods for assessing measurement error (reliability) in variables relevant to sports medicine. Sports Med 1998; 26: 217-238

3 Baker D, Nance S. The relationship between strength and power in professional rugby league players. J Strength Cond Res 1999; 13: 224-229

4 Canavan PK, Vescovi JD. Evaluation of power prediction equations: peak vertical jumping power in women. Med Sci Sports Exerc 2004; 36: $1589-1593$

5 Comfort P, Graham-Smith P, Matthews MJ, Bamber C. Strength and power characteristics in English elite rugby league players. J Strength Cond Res 2011; 25: 1374-1384

6 Cormack SJ, Newton RU, McGuigan MR, Doyle TLA. Reliability of measures obtained during single and repeated countermovement jumps. Int J Sports Physiol Perform 2008; 3: 131-144

7 Dugan EL, Doyle TL, Humphries B, Hasson CJ, Newton RU. Determining the optimal load for jump squats: a review of methods and calculation. J Strength Cond Res 2004; 18: 668-674

8 Duncan MJ, Lyons M, Nevill AM. Evaluation of peak power prediction equations in male basketball players. J Strength Cond Res 2008; 22 : $1379-1381$

9 Folland JP, Williams AG. The adaptations to strength training: morphological and neurological contributions to increased strength. Sports Med 2007; 37: 145-168

10 Gabbett TJ, Gahan CW. Repeated high-intensity efforts activity in relation to tries scored and conceded during rugby league match-play. Int J Sports Physiol Perform 2015; doi:http://dx.doi.org/10.1123/ ijspp.2015-0266

11 Gabbett TJ, Jenkins DG, Abernethy B. Physiological and anthropometric correlates of tackling ability in junior elite and subelite rugby league players. J Strength Cond Res 2010; 24: 2989-2995

12 Gabbett TJ, Seibold AJ. Relationship between test of physical qualities, team selection, and physical match performance in semiprofessional rugby league players. J Strength Cond Res 2013; 27: 3259-3265

13 Gabbett TJA. A comparison of physiological and anthropometric characteristics among playing positions in sub-elite rugby league players. J Sports Sci 2006; 24: 1273-1280

14 Gabbett TJ. Performance changes following a field conditioning program in junior and senior rugby league players. J Strength Cond Res 2006; 20: 215-221

15 Gabbett TJ. Science of rugby league football: a review. J Sport Sci 2005; 23: 961-976

16 Harman EA, Rosenstein MT, Frykman PN, Rosenstein RM, Kraemer WJ. Estimation of human power output from vertical jump. J Appl Sport Sci Res 1991; 5: 116-120

17 Harriss DJ, Atkinson G. Ethical standards in sport and exercise science research: 2016 update. Int J Sports Med 2015; 36: 1121-1124

18 Hertogh C, Hue O. Jump evaluation of elite volleyball players using two methods: jump power equation and force platform. J Sports Med Phys Fit 2002; 42: 300-303

19 Jardine MA, Wiggins TM, Myburgh KH, Noakes TD. Physiological characteristics of rugby players including muscle glycogen content and muscle fibre composition. South Afr Med J 1988; 73: 529-532

20 Johnston RD, Gabbett TJ, Jenkins DG, Hulin BT. Influence of physical qualities on post-match fatigue in rugby league players. J Sci Med Sport 2015; 18: 209-213

21 Johnston RD, Gabbett TJ, Jenkins DG. Influence of playing standard and physical fitness on activity profiles and post-match fatigue during intensified junior rugby league competition. Sports Med 2015; 1 doi:10.1186/s40798-015-0015-y

22 Jones B, Emmonds S, Hind K, Nicholson G, Rutherford Z, Till K. Physical qualities of international female rugby league players by playing position and injury history. J Strength Cond Res 2015; doi:10.1519/ JSC.0000000000001225

23 Kirkpatrick J, Comfort P. Strength, power, and speed qualities in English junior elite rugby league players. J Strength Cond Res 2013; 27 : 2414-2419

24 Klavora P. Vertical-jump tests: a critical review. J Natl 2000; 22: 70-75 
25 Lara AJ, Abián J, Alegre LM, Jiménez L, Aguado X. Assessment of power output in jump tests for applicants to a sport sciences degree. J Sports Med Phys Fitness 2006; 46: 419-424

26 Logan P, Fornasiero D, Abernethy PJ, Lynch K. (2000) Protocols for the assessment of isoinertial strength. In: Gore CJ (eds.). Physiologica Tests for Elite Athletes. Illinois: Human Kinetics; 2000: 200-221

27 McLellan CP, Lovell DI, Gass GC. Markers of postmatch fatigue in professional rugby league players. J Strength Cond Res 2011; 25: 1030-1039

28 McMahon JJ, Jones PA, Comfort PA. correction equation for jump height measuring the just jump system. Int J Sport Physiol Perform 2016 doi:http://dx.doi.org/10.1123/ijspp.2015-0194

29 McMaster DT, Gill N, Cronin J, McGuigan M. The development, retention and decay rates of strength and power in elite rugby union, rugby league and American football: a systematic review. Sports Med 2013; 43: $367-384$

30 Nuzzo JL, Anning JH, Scharfenberg JM. The reliability of three devices using for measuring vertical jump height. J Strength Cond Res 2011; 25: $2580-2590$

31 Quagliarella L, Sasanelli N, Belgiovine G, Moretti L, Moretti B. Powe output estimation in vertical jump performed by young male soccer players. J Strength Cond Res 2011; 25: 1638-1646
32 Sayers SP, Harackiewicz DV, Harman EA, Frykman PN, Rosenstein MT. Cross-validation of three jump power equations. Med Sci Sports Exerc 1999; 31: 572-577

33 Speranza MJA, Gabbett TJ, Johnston RD, Sheppard JM. Muscular strength and power correlated of tackling ability in semi-professional rugby league players. J Strength Cond Res 2015; 20: 2071-2078

34 Tessier JF, Basset FA, Simoneau M, Teasdale N. Lower-limb power cannot be estimated accurately from vertical jump tests. J Hum Kinet 2013; 38: 5-13

35 Till K, Cobley S, O'Hara J, Birightmore A, Cooke C, Chapman C. Using anthropometric and performance characteristics to predict selection in junior UK rugby league players. J Sci Med Sport 2011; 14: 264-269

36 Twist $C$, Highton J. Monitoring fatigue and recovery in rugby league players. Int J of Sports Physiol Perform 2013; 8: 483-489

37 Twist C, Waldron M, Highton J, Burt D, Daniels M. Neuromuscular biochemical and perceptual post-match fatigue in professional rugby league forwards and backs. J Sport Sci 2012; 30: 359-367

38 Waldron $M$, Worsfold PR, Twist C, Lamb $K$. The relationship between physical abilities, ball-carrying and tackling among elite youth rugby league players. J Sports Sci 2014; 32: 542-549

39 Whitmer TD, Fry AC, Forsythe CM, Andre MJ, Lane MT, Hudy A, Honnold $D E$. Accuracy of a vertical jump contact mat for determining jump height and flight time. J Strength Cond Res 2015; 29: 877-881 